\title{
Analisis Google Terjemahan Yang Menggandung Ungkapan Bahasa Seksisme Terjemahan Bahasa Inggris
}

\author{
Muji Endah Palupi \\ Fakultas Komunikasi dan Bahasa \\ Universitas Bina Sarana Informatika \\ Jl. Salemba Tengah No. 45 Paseban, Jakarta Pusat \\ muji.mji@bsi.ac.id
}

\author{
Cara Sitasi : \\ Palupi, M. E. (2019). Analisis Google Terjemahan Yang Mengandung Ungkapan Bahasa Seksisme Terjemahan \\ Bahasa Inggris. Wanastra, 11(1), 01-06.
}

\begin{abstract}
The quality of the language translation machine must match the content of the text message and the results of the translation. between is the accuracy of language and understanding of the results of the translation.. Is the language received same as the target meaning of the language? Do not translate languages with words per word to make sentences. because every language has a different Grammar. Sexist language usually presents stereotypes about name terms for men and women. Sexist language usually presents stereotypes about the name terms for men and women. However, the implicit of meaning more detrimental to women. Sexual language is used to position one gender at the level of subordinate language. there is no equality. Sexism is more suitable for language which is a cultural product of modern society. the term for a woman who is old. English language is called a sexist language because English Language as an International Language. English Language is rich in vocabulary uptake from other countries. so English language is categorized as Modern Language.
\end{abstract}

Keywords: Google Translation, Sexism Language, English Translation

\section{LATAR BELAKANG}

Layanan Google Terjemahan tidak bisa dipungkiri menjadi jembatan penghubung antara orang-orang dari berbagai bahasa di dunia. Besarnya jumlah pengguna. Betapa mesin ini menjadi kebutuhan warganet. Pada 2006. Google akhirnya melahirkan layanan baru bertajuk Google Translate yang. menggunakan mesin penerjemah dari Yahoo dan $A O L$, Saat memakai mesin penerjemah sistim online antara lain mudah digunakan, cepat, bekerja antar perangkat, fiture audio playback untuk mengetahui cara pengucapan.Sistim kerja mesin terjemahan bahasa menggunakan pemodelan statistik lalu meningkat perkembangannya menjadi pemodelan algoritma. Dengan teknologi ini, hasil terjemahan dapat mendekati penerjemah manusia, Google Translate dapat menerjemahkan dari kata menjadi sebuah kalimat. dalam berbagai Bahasa.

Pada sejarah awal Google Terjemahan difokuskan untuk terjemahan Bahasa Inggris, karena Bahasa Inggris dianggap bahasa yang penting saat itu. Tetapi dilain sisi Google Terjemahan juga memiliki beberapa keterbatasan dalam menterjemahka bahasa. Meskipun dapat membantu pembaca untuk memahami isi umum dari teks Bahasa Asing, tetapi tidak memberikan terjemahan akurat. Bahasa yang yang dihasilkan Google Terjemahan sangat berbeda seperti hasil terjemahan dengan logika manusia.
Setiap negara mempunyai pola Tata Bahasa yang berbeda. Kapasitas mesin tidak bisa harus sesuai dengan pola Tata Bahasa. seperti banyak kita jumpai kalimat yang diterjemahkan dengan mesin penerjemah bahasa maka hasil terjemahan agak berbeda bahasanya. Hasil dari terjemahan terlihat rancu atau membingungkan bahasanya.Bahkan ketika kita menterjemahkan antar bahasa, tidak menggunakan tanta baca, maka hasil terjemahan akan berbeda arti.

Bahasa Seksis adalah penggunaan bahasa yang memposisikan salah satu gender pada tataran subordinasi atau tidak setara. Kajian mengenai bahasa seksis atau analisis kata-kata yang merujuk pada seksisme lebih cocok dilakukan pada bahasa yang merupakan produk budaya masyarakat seperti Bahasa Inggris. Anggapan bahwa Bahasa Inggris adalah bahasa seksis didasarkan bahwa terdapat kata atau ungkapan yang menjadikan wanita sebagai objek. Dalam hal ini bahasa yang dipandang mengandung banyak kosakata maupun ungkapan seksis adalah Bahasa Inggris, karena Bahasa Inggris adalah bahasa yang kaya akan perbendaharaan kata. dalam unsur Bahasa inggris banyak sekali serapan kata yang berasal dari negara lain. Khususnya negara di benua Eropa.

Di zaman globalisasi seperti sekarang ini, menguasai bahasa asing merupakan salah satu keterampilan 
yang wajib untuk dimiliki, antara lain Bahasa Inggris. Pelajaran Bahasa Inggris kini sudah menjadi bahan pembelajaran yang sangat penting di setiap tingkat pendidikan di Indonesia.. Kebanyakan orang menerjemahkan suatu bahasa melalui mesin penerjemah disebabkan tidak menguasai bahasa tersebut. Kemudian mereka hanya menghandalkan dengan menggunakan mesin penerjemah Bahasa. untuk mempercepat terjemahan. Oleh sebab itu Jangan menerjemahkan kata demi kata. melaui mesin penerjemah. Namun hal ini harus dihindari karena beberapa kata dalam Bahasa Inggris merupakan sebuah frasa yang jika diartikan kata perkata akan sangat berbeda dengan makna frasa sebenarnya, Orang yang memahami dalam Ilmu Tata Bahasa maka akan mudah membaca gaya bahasa tulisan yang dihasilkan oleh mesin terjemahan.. Dalam penelitian yang akan dikaji adalah :

1. Bagaimanakah cara menerjemahkan Bahasa melalui Google Terjemahan agar hasil dari terjemahan tidak menjadi Bahasa yang rancu?

2. Kenapa Bahasa Inggris dikatagorikan sebagai Bahasa yang menyudutkan kaum wanita?

3. Mengapa hasil terjemahan Bahasa Inggris mengandung unsur Bahasa Seksisme?

\section{METODE PENELITIAN}

Dalam metode penelitian ini penulis menggunakan penelitian descriptive kuantitative dengan disain study kasus yang terpancang dan berorientasi pada produk hasil terjemahan Bahasa. Sumber dari data yang dipilih berdasarkan kreterian teknik mesin terjemahan bahasa dan diskusi dengan polygloter (orang yang memiliki keahlian dalam berbagai ragam bahasa). Dokumen yang dipilih oleh penulis adalah hasil mesin terjemahan. akan tetapi dalam penelitian ini penulis ingin menambahkan sesuatu yang menarik dengan Bahasa yang sederhana agar dapat dipahami dan dimengerti oleh pembaca.

\section{Google Terjemahan}

Pada dekade 1990-an pengembangan mesin translation otomatic mulai kembali berkembang kemajuannya, pada masa awal diciptakan hanya memfokus terjemahan Bahasa Inggris, kini mesin penerjemah bahasa sudah bisa menterjemahkan 40 Bahasa Asing.. Seorang Insinyur IBM bernama Frederick Jelinek mengembangan mesin terjemahan bahasa secara otomatis.

Pada tahun 2006. Google akhirnya melahirkan, layanan barunya bertajuk Google Translate. Google Translate menggunakan sistem bernama SYSTRAN untuk proses penerjemahan. Mesin penerjemah dari Yahoo dan AOL
Pada 2007, Google Translate berubah cara kerjanya dari menggunakan sistim pemodelan statistik menjadi. sistim algoritma. Google Translate bekerja dengan menghimpun begitu banyak translasi yang dilakukan manusia atas jutaan dokumen di dunia. Namun, bicara dalam hal menerjemahkan bukanlah soal mudah. Terutama jika dilakukan mesin penerjemah Bahasa.. Cukup banyak cerita perihal buruknya hasil yang bisa kita ketahui dari hasil terjemahan bahasa yang dilakukan mesin Google Translate, maka seseorang sangat mudah mengenali secara langsung sebuah naskah terjemahan yang dihasilkan dari teknologi mesin.

Berdasarkan dari hasil penelitian Franz-Josef Och Kepala Departemen Terjemahan Google yang telah memenangkan kontes DARPA,

"bahwa untuk kecepatan sistem mesin penerjemah berdasarkan statistik diperlukan suatu koleksi teks paralel dalam dua bahasa yang terdiri lebih dari satu juta kata dan dua koleksi teks lainnya untuk masingmasing bahasa yang terdiri lebih dari satu miliar" (Och Franz- Josef, n.d.)

\section{Bahasa Seksisme}

a. Pengertian Bahasa Seksisme

Seksisme adalah penggunaan kata atau frasa yang berkenaan dengan gender atau individual. Biasanya Bahasa yang digunakan lebih menyudutkan posisi wanita. Seksisme memiliki pengerrtia di bidang ilmu linguistic.khususnya pada nomina atau kata benda. Bahasa umumnya disebut bias gender.

(Wareing, 2007) Bahasa Seksis sebagai bahasa yang merepresentasikan pria dan wanita secara tidak setara. Dalam istilah secara fenomena Bahasa Seksis biasanya hanya menyajikan stereotip-stereotip tentang pria dan wanita yang terkadang merugikan keduanya tapi lebih sering merugikan kaum wanita.

.(Roberton, n.d.) Menurut Parks dan Roberton, berpendapat bahwa, "sexist language includes words, phrases, and expressions that unnecessarily differentiate between women and men or exclude, trivialize, or diminish either gender" Bahasa seksis adalah bahasa yang memposisikan salah satu gender pada tingkat tataran subordinasi (inferior) atau adanya tidak setara. Seksisme lebih cocok dilakukan pada bahasa yang merupakan produk seperti Bahasa Inggris.

b. Sudut Pandang Bahasa Inggris Seksisme Bahasa Inggris adalah bahasa seksis didasarkan terdapat beberapa kata-kata atau ungkapan yang menjadikan wanita menjadi objek tersudutkan. Biasanya wanita dipandang dari segi umur dan penampilannya seperti 


\section{Terjemahan Bahasa Inggris}

Cara kerja pada sistim mesin terjemahan yang menggunakan sistim aplikasi perangkat lunak yang dirancang untuk mendukung proses penerjemahan. Walaupun memiliki konsep serupa, penerjemahan mengunakan mesin penerjemah bahasa tidak dapat disamakan dengan hasil terjemahan logika manusia.

Di zaman globalisasi seperti sekarang ini, menguasai Bahasa Asing merupakan salah satu keterampilan yang wajib untuk dimiliki, pelajaran Bahasa Inggris kini sudah menjadi bahan pembelajaran yang ada di setiap tingkat pendidikan, Karena begitu besar tingkat pengguna Bahasa Inggris didunia sebagai second language, adanya sedikit perbedaan dari segi pengucapan atau pronounceation dan gaya bicara disetiap negara yang menggunakan Bahasa Inggris. Kemungkinan bahasa seksis dalam Bahasa Inggris tersebut saat diterjemahkan kedalam bahasa lain kata tersebut memiliki padanan yang lebih netral.

Engineering Director Google Translate melalui video conference yang telah dtayangkan di Jakarta, Hal itu dimungkinkan karena Google Translate tidak dapat menerjemahkan kata per kata dalam kalimat. Dengan cara memanfaatkan pada sistem neural, sistem penerjemah dapat mengerti sebuah kalimat secara utuh. (Macduff Hughes, n.d.)

(Nababan, Nuraeni, dan Sumardiono, 2012). Sistim model penilaian dari kualitas terjemahan bahasa telah dikembangkan oleh Nababan, Nuraeni, dan Sumardionoyang fokus pada terjemahan dari Bahasa Inggris.Dalam sistim model yang dikembangkan terdapat pada bagian yang membahas kualitas terjemahan dan pembobotan..

Aspek tingkat keakuratan bahasa dan tingkat pemahaman dalam makna hasil terjemahan (Harwan, 2015). Bahwa perlu dalam penerjemah suatu bahasa, apakah bahasa yang diterjemahkan dari satu bahasa ke bahasa lain sesuai dengan makna bahasa sasaran yang dimaksud agar tidak terdapat kalimat yang rancu dari hasil terjemahan bahasa.

\section{PEMBAHASAN}

\section{Difinisi Google Terjemahan}

Google Terjemahan atau translation mechin adalah layanan yang disediakan oleh Google Inc. Untuk menerjemahkan bagian teks atau halaman web bahasa ke bahasa lain. Google Terjemahan juga merupakan cabang linguistic komputasional yang menggunakan perangkat lunak komputer untuk menerjemahkan teks atau ucapan dari berbagai bahasa. Pada tingkat dasar, sistim mesin terjemahan cara kerja dalam bentuk sederhana berupa kata kata dari satu bahasa ke bahasa lainnya. Namun cara itu biasanya tidak dapat menghasilkan terjemahan teks yang bagus, karena diperlukan pengenalan mengenai frasa utuh dan pendekatan kepada bahasa tujuan.

Dengan menggunakan teknik sistim korpus dan data statistik, dapat dilakukan penerjemahan yang lebih kompleks sehingga memungkinkan penanganan yang lebih baik terhadap perbedaan tipologi dalam ilmu linguistic, cara pengenalan frasa, penerjemahan idiom, dan juga penanganan anomali.

Perangkat lunak terjemahan mesin yang ada saat ini umumnya mengizinkan menggunakan berdasarkan domain, sehingga meningkatkan hasil terjemahan dengan membatasi dalam ruang lingkup substitusi yang efektif dalam suatu domain yang menggunakan Bahasa yang formal. Maka dengan bantuan teknikteknik ini, terjemahan mesin telah terbukti bermanfaat sebagai suatu alat bantu manusia dalam proses belajar bahasa.. Namun sistim-sistim yang telah tersedia, tidak mampu untuk menghasilkan dengan kualitas hasil terjemahan yang menyamai penerjemah manusia, terutama jika teks yang diterjemahkan menggunakan bahasa sehari-hari.

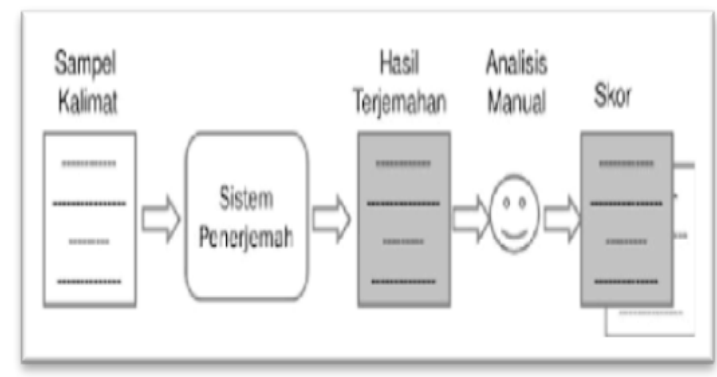

Gambar 1. Cara Kerja Mesin Terjemahan

\section{a. Sistim Kerja Google Terjemahan}

\section{1) Simstim Statistik}

Pemodelan statistik mampu mengatasi permasalahan logika-logika.seperti kamus. Sistim statistik dalam dua bahasa diperlukan suatu koleksi teks paralel dalam dua bahasa tersebut yang terdiri lebih dari satu juta kata dan dua koleksi teks lainnya untuk masing-masing bahasa yang terdiri lebih dari satu miliar kata.

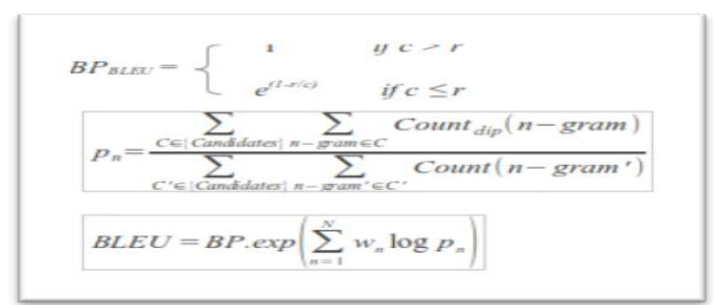

Gambar 2. Sistim Pemodelan Statistik 
2) Sistim Algoritma

Pemodelan algoritma diadaptasi berdasarkan datadata yang banyak dilakukan. Data yang ditemukan berdasarkan frekwensi dari data yang paling banyak ditemukan.data linguistik dalam jumlah yang sangat besar ini, Google menggunakan dokumen PBB. Sistim cara kerja menggunakan algoritma lebih mudah, artinya menerjemahkan berdasarkan rumus yang dibuat oleh sistim pemrograman. Rumus ini didapatkan dari jumlah banyaknya data-data berupa penerjemahan bahasa yang telah deprogram dalam suatu sistim pemograman.

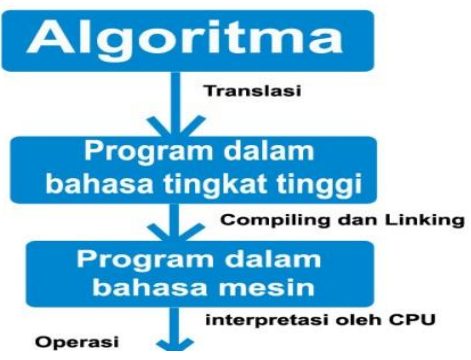

Gambar 3. Sistim Pemodelan Algoritma Mesin

Terjemahan

\section{Bahasa Seksisme}

a. Bahasa Seksisme dalam Bahasa Inggris Anggapan mengenai bahwa Bahasa Inggris adalah bahasa seksis didasarkan terdapat beberapa kata atau ungkapan yang menjadikan wanita menjadi objek tersudutkan. (Roberton, n.d.)

\begin{tabular}{c|c}
\hline Bahasa Seksisme & Gender \\
\hline Hag & Wanita tua \\
& Wanita wajah keriput \\
\hline
\end{tabular}

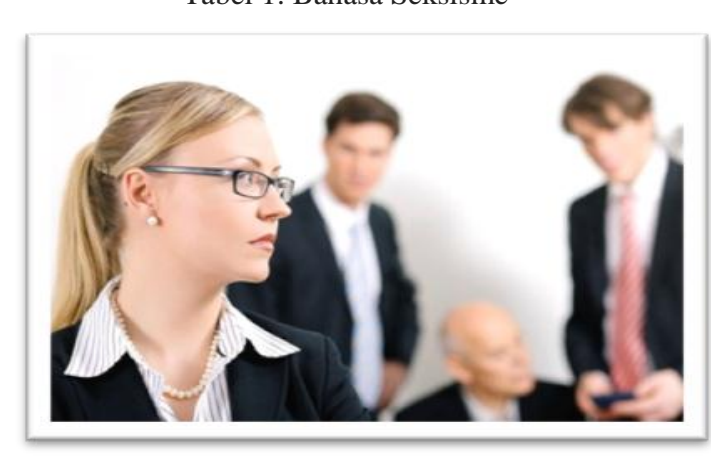

Gambar 1. Wanita dinomor duakan

Dari makna yang diberikan, dapat diketahui adanya unsur penampilan, umur, dan gender. Pada makna kedua kata tersebut yang seolah lebih merendahkan dan menghina kaum wanita, khususnya bagi wanita yang sudah tidak lagi muda. Pada makna kedua kata tersebut yang seolah lebih merendahkan dan menghina kaum wanita, khususnya bagi wanita.(Pattalung, 2008)

b. Sudut Pandang Bahasa Inggris Seksisme Dalam istilah secara fenomena bahwa dikatakan Dalam Tata Bahasa Turki tidak ada perbedaan gender. Türkiye ortak bir dildir ve erkekler ve kadınlar arasinda fark yoktur. Her şey "O". Cümleler, cümle bağlamından bilinebilir. Türkçe cümleleri google çeviri kullanarak Ingilizce'ye çevirirsek, cümle garip görünecek ve cinsiyeti ayırt edecektir. Google Translate, Türkçe olmayan cinsiyet cezalarını cinsiyetçi cümlelere çevirir. (Shams, n.d.)

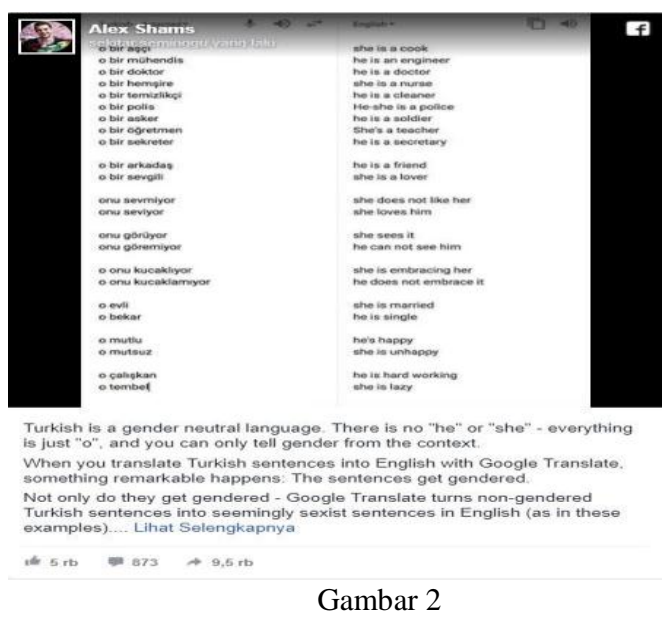

. Terjemahan Bahasa Turki ke Bahasa Inggris menjadi pengertian yang aneh

\section{Terjemahan Bahasa Inggris}

a. Pengertian Terjemahan

Penerjemahan dalam sistim kerja mengunakan mesin penerjemah bahasa biasanya tidak dapat disamakan dengan hasil terjemahan logika manusia. Applikasi mesin terjemahan bahasa diciptakan tujuannya untuk mempermudah orang belajar bahasa tanpa harus melihat buku kamus. Para ahli ilmuan mencoba sistim yang lebih baru, perkembangan teknologi semakin maju maka dibuatlah kamus secara online . Awal pertama kali disiptakannya. Mesin penerjemah bahasa hanya dikhususkan untuk menterjemahkan antar bahasa ke dalam Bahasa Inggris karena orang lebih banyak menggunakan Bahasa Inggris. (Budiwati, 2011)

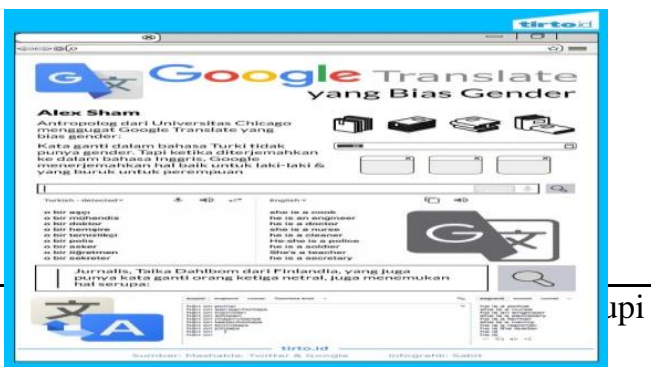


Gambar 1. Google Translate Bias Gender

b. Kerancuan Terjemahan Bahasa Inggris

Bahasa Inggris adalah Bahasa Internasional Bahasa inggris sudah menjadi Trend sebagai Bahasa No 1 di dunia.

\begin{tabular}{c|c}
\hline Inggris & Türkiye \\
\hline I & Ben \\
You & Sen / Siz \\
We & Biz \\
They & Onlar \\
She & O \\
He & O \\
It & O \\
\hline
\end{tabular}

Tabel 1. Perbedaan Subjek

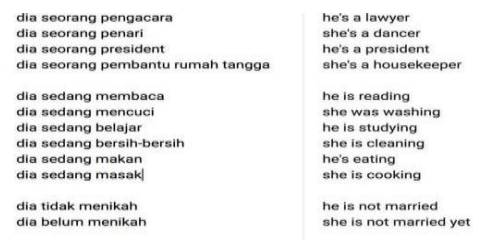

Gambar 2. Bias Gender hasil terjemahan

Bahasa Indonesia tidak ditemukan bahasa seksis yang bias gender,.Beda dengan Bahasa Inggris yang menyesuaikan kata ganti orang berdasarkan jenis kelamin. Sementara dalam bahasa-bahasa di negaranegara Eropa seperti Inggris, Perancis, dan Jerman, gender masuk ke dalam perhitungan utama struktur gramatikal

\section{KESIMPUILAN}

Kualitas mesin penerjemah bahasa atau pesan teks bersumber pada bahasa yang akurat. .Dari aspek tingkat keakuratan bahasa,. tingkat pemahaman dalam hasil terjemahan. Apakah bahasa yang diterjemahkan sesuai dengan makna bahasa sasaran ? agar tidak terdapat kalimat yang rancu dari hasil terjemahan bahasa. Jangan menerjemahkan bahasa melalui mesin penerjemah atau Google Translator kata perkata dalam membuat kalimat. karena setiap bahasa menpunyai Tata Bahasa yang berbeda. Bahasa Seksis biasanya lebih menyajikan stereotipstereotip tentang adanya istilah nama untuk pria dan wanita. terkadang merugikan keduanya. Akan tetapi makna yang tersirat lebih sering merugikan kaum wanita. Dalam Bahasa Seksis penggunaannya untuk memposisikan salah satu gender pada tataran bahasa subordinasi (inferior) atau tidak adanya kesetaraan. Seksisme lebih cocok pada bahasa yang merupakan produk budaya masyarakat moderen. kata yang khususnya wanita yang sudah tidak lagi muda.. katakata atau ungkapan yang tergolong mengandung makna istilah seksis. Awalnya diciptakan oleh masyarakat yang dipengaruhi oleh sudut pandangan terhadap kedua jenis gender. Bahasa yang dipandang mengandung banyak kosakata maupun ungkapan Bahasa Seksis adalah Bahasa Inggris. Hal ini juga disebabkan karena Bahasa Inggris sebagai Bahasa Internasional. Bahasa Inggris kaya akan serapan perbendaharaankata Bahasa dari negara lain. Dengan demikian maka Bahasa Inggris dikatagorikan bahasa dikatagorikan sebagai Bahasa Moderen.

\section{DAFTAR ACUAN}

Budiwati, T. R. (2011). REPRESENTASI WACANA GENDER DALAM UNGKAPAN BERBAHASA INDONESIA DAN BAHASA INGGRIS : ANALISIS WACANA KRITIS. Kawistara, 1(3), 298-310.

Harwan, R. (2015). Model Terjemahan Bahasa Inggris Indonesia Ragam Negara. In model terjemahan bahasa inggris indonesia bragam negara.

Macduff Hughes. (n.d.). Engineering Director Google Translate melalui video conference yang telah dtayangkan di Jakarta, Hal itu dimungkinkan karena Google Translate tidak dapat menerjemahkan kata per kata dalam kalimat. Dengan cara memanfaatkan pada sistem neura.

Nababan, Nuraeni, dan Sumardiono. (2012). Sistim model penilaian dari kualitas terjemahan bahasa.

Och Franz- Josef. (n.d.). ". Teory Reaches, Developing of Translation Mechin Moderen.

Palupi, M. E. (2019). Analisis Google Terjemahan Yang Mengandung Ungkapan Bahasa Seksisme Terjemahan Bahasa Inggris. Wanastra, 11(1), 01-06.

Pattalung, P. N. (2008). An Analysis of Sexist Language in ESL. Texas: Universitas of north texas.

Roberton, M. P. dan. (n.d.). , berpendapat bahwa, "sexist language includes words, phrases, and expressions that unnecessarily differentiate between women and men or exclude, trivialize, or diminish either gender".

Shams, A. (n.d.). Görüş :Türkiye ortak bir dildir ve 
erkekler ve kadınlar arasinda fark yoktur. Her şey " $O$ ”.

Wareing. (2007). 106. Bahasa Seksis Sebagai Bahasa Yang Merepresentasikan Pria Dan Wanita Secara Tidak Setara, 106.

\section{PROFIL PENULIS}

Muji Endah Palupi lahir di Jakarta pada tahun 1973. Penulis memperoleh gelar Sarjana Sastra, Jurusan Bahasa dan Sastra Inggris di STIBA IEC Pada tahun 2012 dan Gelar Magister, Fakultas Pendidikan Bahasa Inggris di Universitas Indraprasta PGRI Pada tahun 2015. Penulis sebagai Dosen Bahasa Inggris Fakultas Komunikasi dan Bahasa di Universitas Bina Sarana Informatika dari tahun 2013 hingga saat ini. Aktifitas lain Penulis sebagai Tutor Bahasa Inggris di Bimbingan Belajar Primagama dan Guru Bahasa Turki. Penulis juga aktif di Ruhum Türkçe Kursu, KSE. Selain itu Penulis juga di acara Seminar, Workshop dan kegiatan lain yang berkaitan dengan bidang pendidikan khususnya Ilmu Bahasa Asing. Bahasa sebagai jembatan komunikasi antar Bangsa Bahasa adalah alat pemersatu Bangsa. Dengan Bahasa kita bisa memahami arti kehidupan dibelahan bumi. 